DOI: $10.17516 / 1999-494 X-0354$

УДК 678: 620.172: 539.376

\title{
Experimental Studies of Creep \\ of Unidirectional Composite Material \\ of Composite Overwrapped Pressure Vessel
}

\author{
Nikita V. Eremin*a, \\ Egor V. Moskvichev ${ }^{a}$ and Kirill A. Pasechnik ${ }^{b}$ \\ ${ }^{a}$ Federal Research Center \\ for Information and Computational Technologies \\ Krasnoyarsk, Russian Federation \\ ${ }^{b}$ Reshetnev Siberian State University of Science and Technology \\ Krasnoyarsk, Russian Federation
}

Received 23.07.2021, received in revised form 20.08.2021, accepted 21.09.2021

\begin{abstract}
Experimental studies of creep of a composite material of a composite overwrapped pressure vessel are presented. Composite material was an unidirectional tape based on IMS60 carbon fibers and epoxy resin. Creep tests were carried out at various loads and temperatures, taking into account the stress level in structure and measured glass transition temperature of the material. For testing, special equipment was used to install specimens in the grips of the testing machine. According to the test results, the creep curves were obtained. Creep curves according to Findlay's model are presented. For the stage of steady-state creep, the variation of the creep rate at different temperatures were determined, and the average value of the creep rate was calculated for all tested specimens. The results of the obtained data can be used in numerical models for predicting strains of a composite overwrapped pressure vessel under creep conditions.
\end{abstract}

Keywords: creep, strain rate, composite material, composite overwrapped pressure vessel.

Citation: Eremin N. V., Moskvichev E. V., Pasechnik K. A. Experimental studies of creep of unidirectional composite material of composite overwrapped pressure vessel, J. Sib. Fed. Univ. Eng. \& Technol., 2021, 14(6), 731-741. DOI: 10.17516/1999-494X-0354

(C) Siberian Federal University. All rights reserved

This work is licensed under a Creative Commons Attribution-Non Commercial 4.0 International License (CC BY-NC 4.0).

* Corresponding author E-mail address: kaizoku813@gmail.com 


\title{
Экспериментальные исследования ползучести
}

\section{однонаправленного композитного материала \\ металлокомпозитного бака высокого давления}

\author{
Н. В. Еремина ${ }^{a}$ Е. В. Москвичева ${ }^{\text {a }}$ К. А. Пасечник ${ }^{0}$ \\ ${ }^{a}$ Федеральный исследовательский изентр \\ информационных и вычислительных технологий \\ Российская Федераџия, Красноярск \\ ${ }^{6}$ Сибирский государственный университет науки \\ и технологий им. академика М. Ф. Решетнева \\ Российская Федерация, Красноярск
}

\begin{abstract}
Аннотация. В работе изложены экспериментальные исследования ползучести композитного материала металлокомпозитного бака высокого давления. Композитный материал представлял собой однонаправленную ленту на основе углеродных волокон IMS60 и эпоксидного связующего ЭД-И. Испытания на ползучесть проводились при различных нагрузках и температурах с учетом уровня напряжений в конструкции и измеренной температуры стеклования материала. Для испытаний применялась специальная оснастка для установки образцов в захваты испытательной машины. По результатам испытаний построены кривые ползучести образцов. Представлены кривые ползучести по модели Финдли. Для стадии установившейся ползучести определены диапазоны изменения скорости ползучести при различных температурах и рассчитано усредненное значение скорости ползучести по всем испытанных образцам. Полученные результаты могут быть использованы в численных моделях прогнозирования ресурса металлокомпозитных баков высокого давления в условиях ползучести.
\end{abstract}

Ключевые слова: ползучесть, скорость ползучести, композитный материал, металлокомпозитный бак высокого давления.

Цитирование: Еремин, Н. В. Экспериментальные исследования ползучести однонаправленного композитного материала металлокомпозитного бака высокого давления / Н. В. Еремин, Е. В. Москвичев, К. А. Пасечник // Журн. Сиб. федер. ун-та. Техника и технологии, 2021, 14(6). С. 731-741. DOI: 10.17516/1999-494X-0354

\section{Введение}

Металлокомпозитные сосуды давления, изготовленные методом непрерывной намотки, могут эксплуатироваться в течение длительного времени. Одним из примеров является металлокомпозитный бак высокого давления (МКБВД), устанавливаемый на космических аппаратах со сроком активного существования 15 лет [1]. В течение эксплуатации в МКБВД могут проходить процессы релаксации напряжений, развиваться накопленные повреждения как в силовой композитной оболочке, так и в металлическом лейнере. При этом композитный материал подвержен изменению физико-механических свойств при длительных механических и температурных воздействиях. В совокупности эти процессы могут оказывать значительное влияние на прочность, геометрическую стабильность и ресурс МКБВД под нагрузкой.

Для оценки длительной прочности и ресурса целесообразно проводить испытания МКБВД при длительном нагружении внутренним давлением. Однако такие испытания требуют большого количества времени и затрат, труднореализуемы на практике, а в ряде случаев невозможны [1, 
2]. Это обуславливает необходимость проведения относительно кратковременных механических испытаний образцов композитного материала МКБВД на ползучесть при повышенных температурах, что и являлось целью данной работы.

В настоящее время испытания на ползучесть проводят с целью изучения влияния различных факторов, характерных для композитных материалов. Так, авторы работ [3, 4] исследовали вязкоупругое поведение композитного материала в широком диапазоне напряжений при постоянной температуре $90{ }^{\circ} \mathrm{C}$. Было определено, что материал имеет нелинейное поведение в широком диапазоне напряжений. Работа [5] направлена на исследования ползучести композитного материала на основе углеродных волокон и эпоксидного связующего при растяжении и изгибе. Д. Басаидом и др. [6] было изучено влияние различных видов матрицы в составе композитного материала на его поведение при ползучести. Было определено, что разрушение в условиях ползучести для углеродных волокон и эпоксидного связующего происходит после 30 ч при уровне напряжений в $80 \%$ от предела прочности при растяжении.

Исследования, отраженные в работе [7], позволили определить, что композитные материалы чувствительны к воздействию первоначальных деформаций в условиях ползучести за счет высокого продольного модуля упругости и объемной доли волокна. По прошествии 720 ч эксперимента средние значения продольных деформаций составили от 1,35 до 1,63 \%, при этом скорость ползучести была незначительной. Полученные результаты позволили определить, что в течение 12000 ч продольные деформации в материале не увеличились. Донг Янгом и др. [8] были изготовлены лабораторные образцы в виде сухожилия на основе углеродного волокна и эпоксидноого связующего с объемной долей $65 \%$. Нагрузка прикладывалась в диапазоне 69-85 \% от предела прочности при растяжении в течение 1000 ч. Было обнаружено, что деформации ползучести увеличиваются с повышением уровня напряжений в образце. Таким образом, отслеживается явная зависимость напряжений от деформаций с течением времени. Остаточная прочность образцов после испытаний на ползучесть была снижена на 4,54 \%, а модуль упругости увеличился на $6,99 \%$ от первоначального значения. С использованием модели прогнозирования ползучести были определены деформации спустя $10^{6}$ ч, уровень деформаций в образцах увеличился с 1,12 до $1,87 \%[8,9]$. Исследования, отраженные в работе [10], позволили определить, что при комнатной температуре в условиях длительной статической нагрузки в композитном материале не возникает критических деформаций в течение 30 ч.

Как показывает анализ проведенных исследований, волокна и матрица могут испытывать эффекты ползучести [11, 12], что может в значительной степени повлиять на стабильность, прочность и ресурс конструкций из композитных материалов. Это особенно важно для ответственных конструкций в аэрокосмической области, где уровни напряжений и температур могут быть высокими. Таким образом, цель данной работы, которая заключается в экспериментальном исследовании ползучести композитного материала МКБВД, актуальна. Для достижения данной цели потребовалось решение следующих задач:

- определение температуры стеклования композитного материала;

- обоснование программы испытаний образцов на ползучесть;

- проведение испытаний на ползучесть при различном уровне напряжений и температур.

$$
-733-
$$




\section{Определение температуры стеклования}

Температура стеклования является одной из основных характеристик композитного материала. При ее достижении происходит изменение ряда физических свойств, таких как плотность, жесткость и теплопроводность [13]. Матрица в композитном материале при температурах ниже температуры стеклования находится в твердом состоянии, а при температурах выше - в высокоэластическом. При этом модуль упругости и предел прочности композитного материала снижаются. Кроме того, в работе [14] было показано, что вязкоупругие свойства эпоксидной матрицы наряду с характеристиками волокон значительно влияют на ползучесть композитного материала. Так, при повышении температуры испытаний композитного материала в условиях длительной статической нагрузки проявляется заметный рост деформаций [10]. Это обуславливает необходимость определения температуры стеклования для исследуемого композитного материала, что позволит задать температурный диапазон для последующих испытаний на ползучесть.

Температура стеклования определялась на образцах из композитной оболочки МКБВД путем их испытания по ГОСТ Р 55135-2012 с применением дифференциального сканирующего калориметра TA Instruments DSC25. Метод испытания заключался в измерении общего, обратимого и необратимого тепловых потоков на единицу массы образца в зависимости от температуры. Перед испытанием образцы взвешивали с точностью до 0,1 мг, после чего помещали в камеру прибора, где охлаждали до минус $10{ }^{\circ} \mathrm{C}$ и нагревали до $180^{\circ} \mathrm{C}$ со скоростью $3^{\circ} \mathrm{C} / \mathrm{Mин}$. Полученные в процессе испытаний кривые тепловых потоков для одного из образцов представлены на рис. 1 .

При достижении температуры стеклования теплоемкость образца изменяется, что на кривой обратимого теплового потока проявляется в виде S-образного перегиба. Таким образом, в точке перегиба кривой определялась экспериментальная температура стеклования. Исходя из полученных данных средняя температура стеклования композитного материала МКБВД составила $105,3^{\circ} \mathrm{C}$.

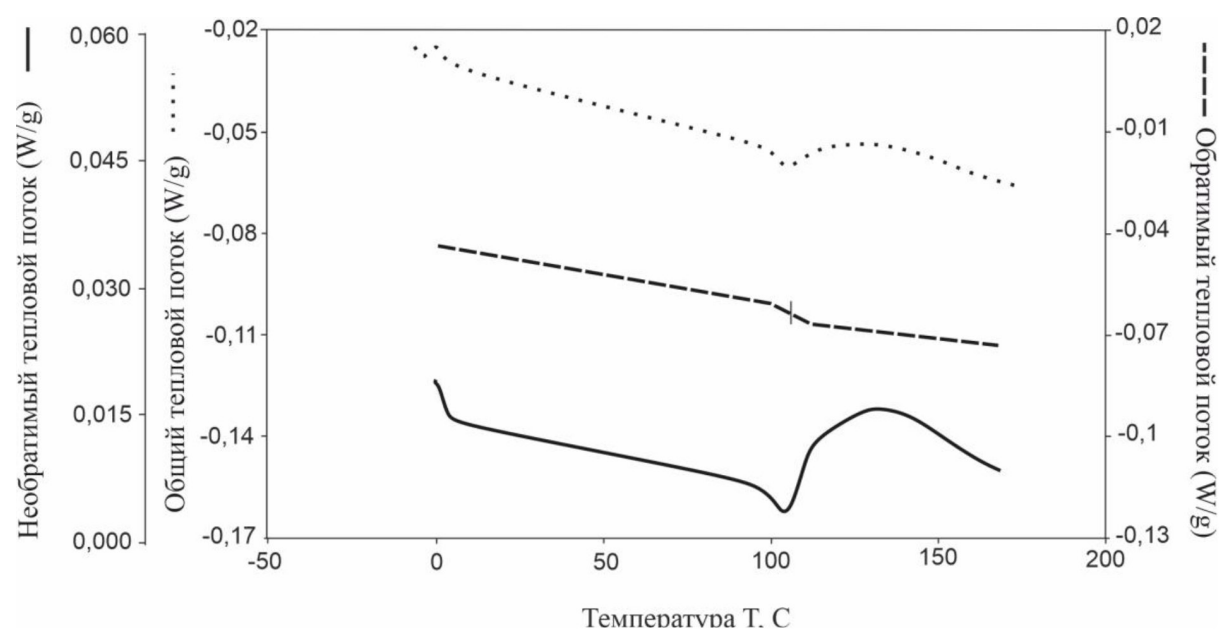

Рис. 1. Температурная зависимость общего, обратимого и необратимого тепловых потоков

Fig. 1. Temperature dependence of the total, reversible and irreversible heat flux 


\section{Испытания на ползучесть}

Композитная оболочка МКБВД состоит из множества слоев однонаправленной композитной ленты, непрерывно уложенной по геодезической траектории под разными углами. Композитная лента представляет собой плоский пучок однонаправленных углеродных волокон IMS60, пропитанных эпоксидным связующим ЭД-И [15]. Характеристики физико-механических свойств композитной ленты и ее компонентов представлены в табл. 1.

Как показывают проведенные ранее численные и экспериментальные исследования $[16,17]$, механические свойства композитной ленты являются определяющими при оценке напряженно-деформированного состояния и прочности МКБВД. В составе слоев композитной оболочки лента работает в условиях двухосного напряженного состояния. Однако преимущественно она находится под действием растягивающих напряжений [16]. При рабочем давлении МКБВД действующие напряжения в ней не превышают 1000 МПа. Таким образом, для исследования ползучести композитного материала МКБВД целесообразно проводить длительные испытания образцов композитной ленты при растяжении в диапазоне от 800 до 1200 МПа. При этом повышение температуры испытаний до температуры, близкой к температуре стеклования, позволит быстрее проявиться эффектам ползучести в материале, тем самым снизив длительность эксперимента $[18,19]$.

Для изготовления образцов на ползучесть из композитной оболочки МКБВД были вырезаны плоские однонаправленные композитные ленты длиной 150 мм и шириной от 10 до 21 мм. Средняя толщина лент составляла 0,3 мм. Длина рабочей части в среднем равнялась 90 мм. На концы лент приклеивались композитные накладки толщиной 3 мм для жесткой фиксации образцов в захватах испытательной машины (рис. 2).

Основные методы испытаний композитных материалов на ползучесть при растяжении представлены в стандартах ГОСТ Р 57714-2017 и ASTM D7337 / D7337M-12(2019). С учетом данных методик испытания на ползучесть проводили на электромеханической испытательной машине ATS-2330 (рис. 3a), оборудованной термокриокамерой ATS-3710 (рис. 3б).

Для измерения деформаций использовался усредняющий экстензометр серии 4124A с датчиками перемещения Heidenhain MT1271. Работы выполнялись в Инженерно-испытательном центре ФИЦ ИВТ.

Для соосной установки образцов в испытательной машине была изготовлена специальная оснастка (рис. 4).

Таблица 1. Физико-механические свойства композитной ленты и ее компонентов Table 1. Physical and mechanical properties of composite tape and its components

\begin{tabular}{|l|c|c|c|}
\hline \multicolumn{1}{|c|}{ Характеристика } & Волокно & Матрица & Композитная лента \\
\hline Модуль упругости, ГПа & 290 & 3 & 115,7 \\
\hline Предел прочности при растяжении, ГПа & 5,8 & 0,5 & 2,06 \\
\hline Коэффициент Пуассона & 0,28 & 0,32 & 0,32 \\
\hline Температура стеклования, ${ }^{\circ} \mathrm{C}$ & 250 & 57 & 105,3 \\
\hline
\end{tabular}




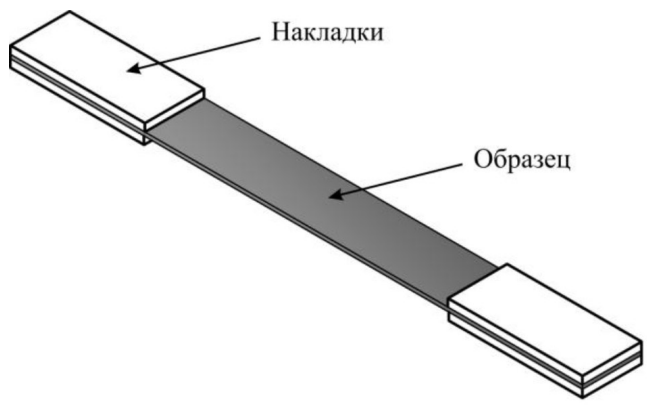

a)

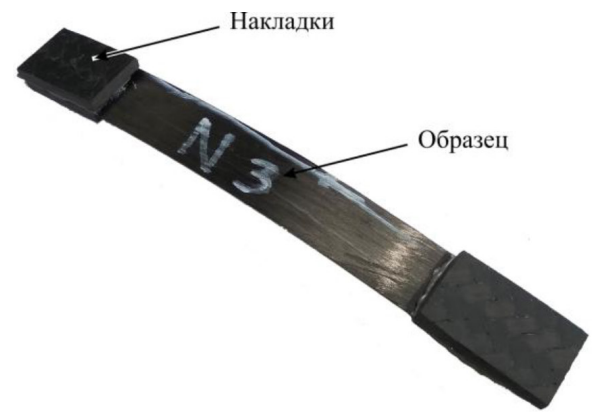

б)

Рис. 2. Композитная лента для испытаний на ползучесть: а - эскиз; б - фотография

Fig. 2. Composite tape for creep tests: $a-$ sketch; $b-$ photo

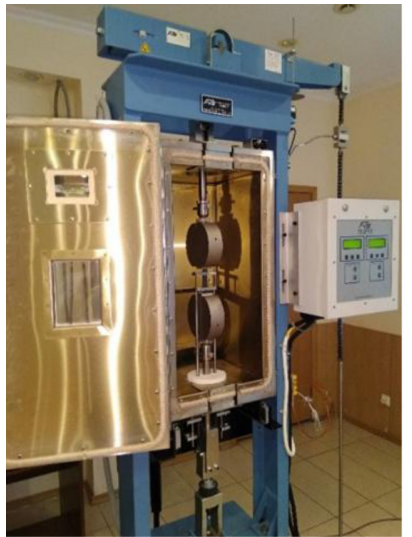

a)

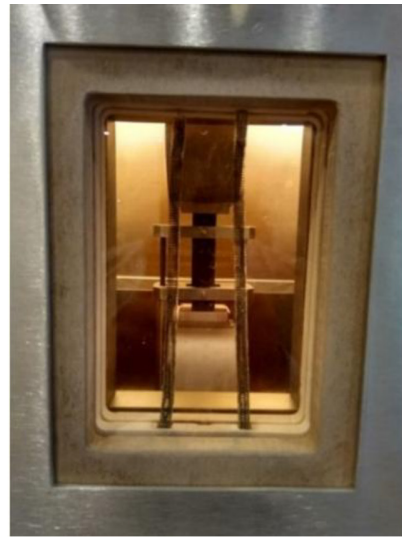

б)

Рис. 3. Испытательная установка: а - электромеханическая испытательная машина ATS2330; б термокриокамера

Fig. 3. Test machine: a - electromechanical testing machine ATS2330; b-environmental chamber

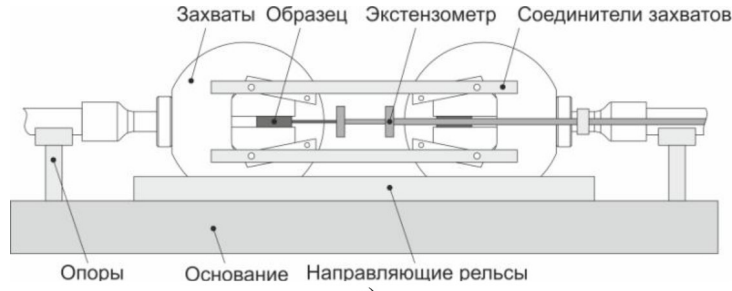

a)

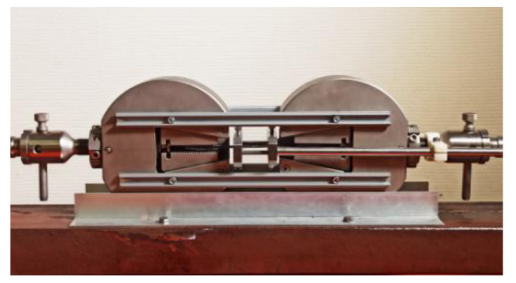

б)

Рис. 4. Специальная оснастка для установки лабораторного образца в захваты испытательной машины: а - схема; б - фотография

Fig. 4. Special equipment for placing the specimen in the grips of the testing machine: $a-s c h e m e ; b-$ photo 
Захваты с тягами и экстензометром устанавливали на две регулируемые опоры между направляющими рельсами. Образец для испытаний помещали в захватах, выравнивали вдоль оси нагружения и зажимали. Далее захваты жестко соединялись между собой и совместно устанавливались в испытательную машину вместе с образцом и экстензометром. После установки захваты разъединялись и производилось предварительное нагружение образца малым усилием для выборки люфтов в нагружающей цепи. Данный подход позволил обеспечить симметричное и равномерное растяжение образца, что является важным при длительном эксперименте.

В ходе эксперимента было испытано девять образцов при различных условиях. Образцы испытывали при нагрузке 800, 1000, 1200 МПа и температуре 70,90 и $110{ }^{\circ} \mathrm{C}$. Измерительная база экстензометра задавалась в диапазоне от 36 до 47 мм. Продолжительность испытания каждого образца составляла не менее 250 ч.

Для описания экспериментальных данных ползучести композитного материала применялась модель Финдли [20]. Выбор данной модели обусловлен хорошей сходимостью с экспериментальными данными при исследованиях композитных материалов, а также простотой вычисления ее параметров [21]. Степенной закон Финдли описывается следующим образом:

$$
\varepsilon(t)=\varepsilon_{0}+A \cdot t^{n}
$$

где $\varepsilon(t)$ - деформации ползучести во времени $t ; \varepsilon_{0}$ - начальные упругие деформации; $A-$ амплитуда переходной ползучести; $n$ - постоянная, не зависящая от напряжений.

\section{Анализ результатов}

По завершении испытаний были обработаны данные измерений и построены кривые ползучести в координатах «деформация-время», которые представлены на рис. 5-7.

На графиках рис. 5-7 наблюдаются характерные участки неустановившейся и установившейся стадий ползучести. Длительность стадии неустановившейся ползучести составляет

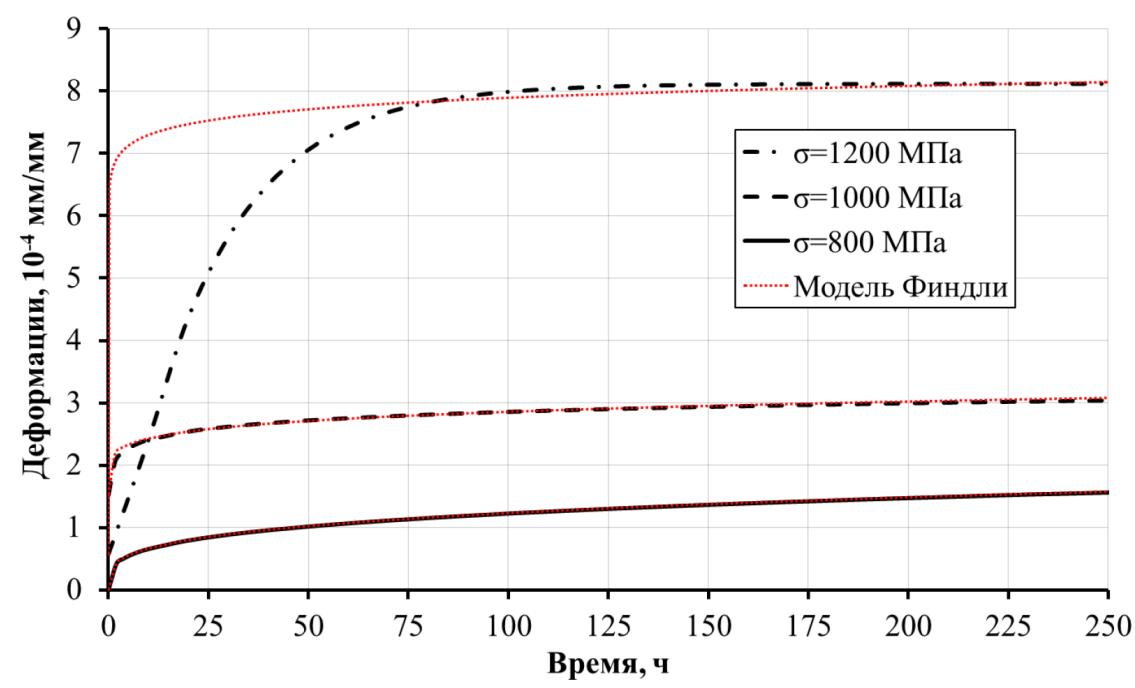

Рис. 5. Кривые ползучести при температуре $70^{\circ} \mathrm{C}$

Fig. 5. Creep curves at $70^{\circ} \mathrm{C}$ 


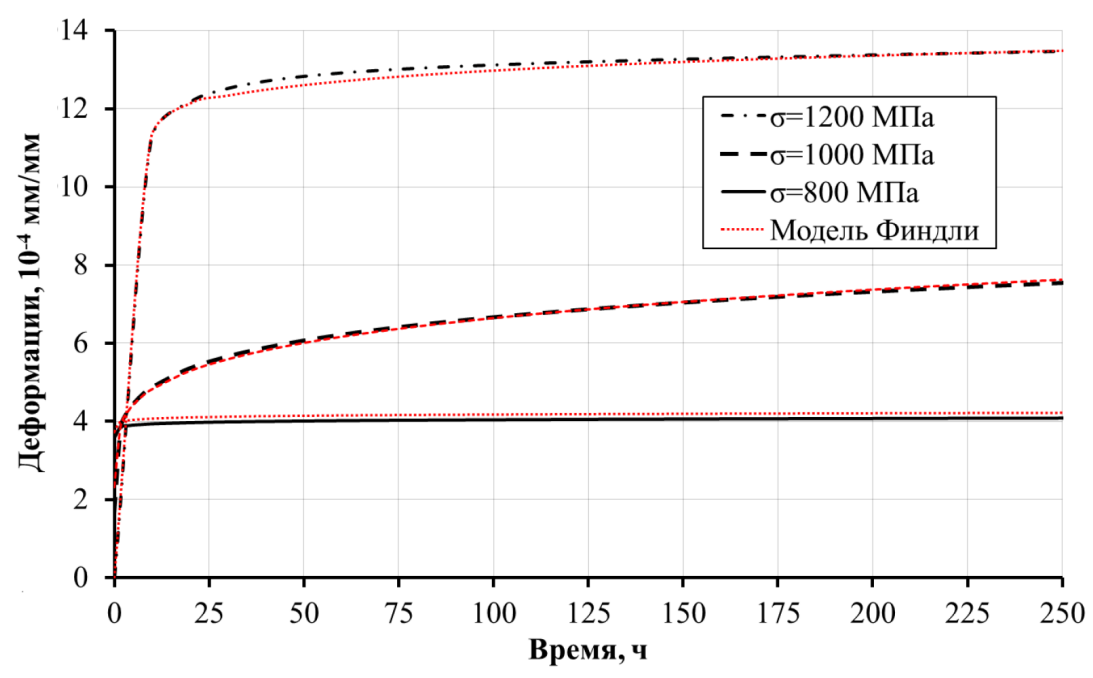

Рис. 6. Кривые ползучести при температуре $90{ }^{\circ} \mathrm{C}$

Fig. 6. Creep curves at $90{ }^{\circ} \mathrm{C}$

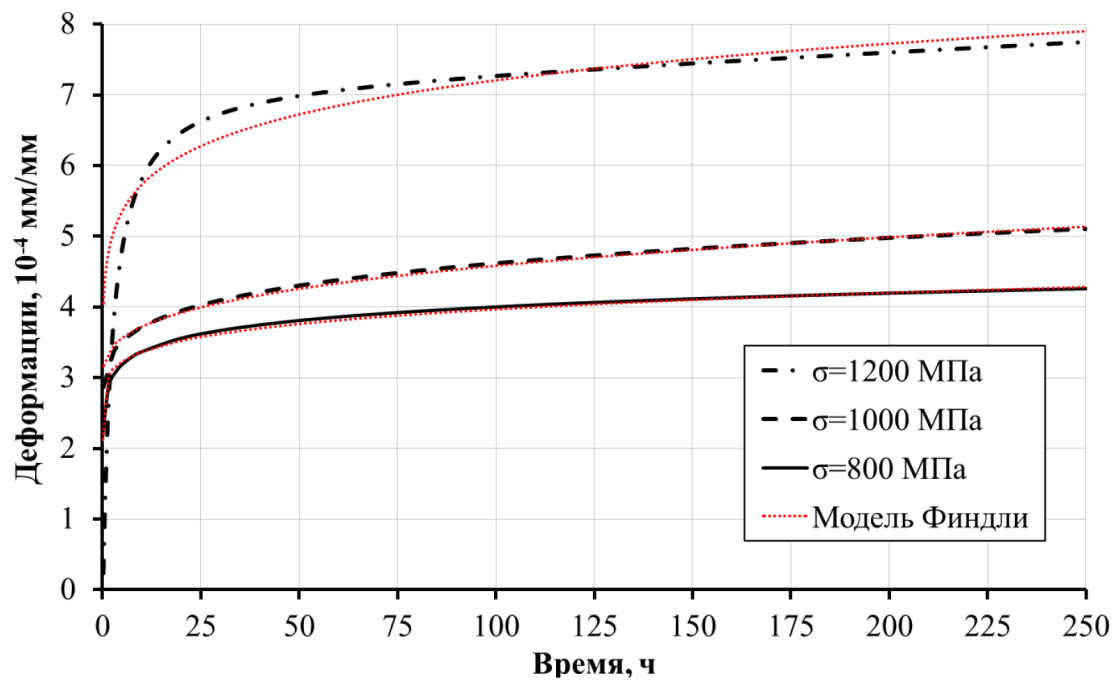

Рис. 7. Кривые ползучести при температуре $110^{\circ} \mathrm{C}$

Fig. 7. Creep curves at $110^{\circ} \mathrm{C}$

от 50 до 100 ч в зависимости от образца и сопровождается высокой скоростью роста деформаций. После перехода на стадию установившейся ползучести деформации увеличиваются с меньшей скоростью по закону, близкому к линейному.

На кривых ползучести прослеживается характерное влияние нагружающего напряжения и температуры испытаний на уровень деформаций образцов. Среднее значение максимальных деформаций составляет $6 \cdot 10^{-4}$ мм/мм. Однако для некоторых образцов уровень деформаций значительно выше. Это можно объяснить влиянием случайных структурных свойств, таких как объемное содержание волокон, наличие пор и дефектов. Вследствие это- 
Таблица 2. Параметры модели Финдли

Table 2. Findley's model parameters

\begin{tabular}{|c|c|c|c|c|}
\hline \multirow{2}{*}{$\mathrm{T},{ }^{\circ} \mathrm{C}$} & $\sigma, \mathrm{M \Pi а}$ & $\varepsilon_{0}, 10^{-4}$ & $A, 10^{-4}$ & $\mathrm{n}$ \\
\hline \multirow{3}{*}{70} & 800 & 0 & 0,36 & 0,269 \\
\cline { 2 - 5 } & 1000 & 1,52 & 0,62 & 0,168 \\
\cline { 2 - 5 } & 1200 & 0,57 & 6,18 & 0,037 \\
\hline \multirow{3}{*}{90} & 800 & 0 & 3,97 & 0,011 \\
\cline { 2 - 5 } & 1000 & 1,66 & 2,02 & 0,196 \\
\hline \multirow{3}{*}{110} & 1200 & 0 & 10,7 & 0,171 \\
\cline { 2 - 5 } & 800 & 2,13 & 0,84 & 0,306 \\
\cline { 2 - 5 } & 1000 & 2,87 & 0,42 & 0,104 \\
\hline
\end{tabular}

го композитный материал имеет широкий разброс характеристик механических свойств, вариация которых может достигать до 22 \% [15]. Таким образом, в процессе ползучести может происходить локальное разрушение и сдвиг волокон, что приводит к росту деформаций образца.

Как следует из рис. 5-7, модель Финдли хорошо описывает полученные экспериментальные данные на стадии установившейся ползучести, что позволяет ее использовать в расчетах при длительном нагружении. Определенные параметры для модели Финдли представлены в табл. 2.

Диаграммы ползучести композитного материала, полученные при испытаниях, изменяются от образца к образцу. Это можно объяснить тем, что при повышенных температурах происходит изменение физических свойства матрицы и композитный материал переходит в высокоэластическое состояние, при котором возникает проскальзывание между волокнами и матрицей. Это приводит к неравномерному снижению механических свойств композитного материала, что отражается на диаграмме ползучести образца. Таким образом, неоднородность структуры вносит значительный вклад в поведение композитного материала в условиях длительных механических и температурных воздействий.

По полученным экспериментальным данным была определена скорость установившейся ползучести для каждого образца по формуле

$$
\dot{\varepsilon}=\frac{\Delta l}{l_{0} \Delta t},
$$

где $\Delta l$ - абсолютное приращение длины образца за время $\Delta t ; l_{0}$ - расчетная длина образца.

Период времени $\Delta t$ выбирали в диапазоне от 100 до 250 ч с учетом наилучшего соответствия участка установившейся ползучести линейной аппроксимации. Определенные таким образом скорости ползучести представлены в табл. 3.

Рассчитанные скорости ползучести имеют большой разброс значений. Поскольку зависимость скорости ползучести от температуры не закономерна, то результаты экспериментов были объединены в одну выборку. Усредненная скорость ползучести по всем испытанным образцам составила $1,75 \cdot 10^{-7} \cdot 1 /$ ч.

$$
-739-
$$


Таблица 3. Скорости ползучести в зависимости от температуры испытаний

Table 3. Creep rates depending on test temperature

\begin{tabular}{|c|c|c|c|}
\hline $\mathrm{T},{ }^{\circ} \mathrm{C}$ & 70 & 90 & 110 \\
\hline$\dot{\varepsilon}, 10-7 \cdot 1 /$ ч & $0,0664-1,72$ & $1,12-4,22$ & $1,17-3,38$ \\
\hline
\end{tabular}

\section{Заключение}

В работе проведены испытания композитной ленты из оболочки МКБВД на ползучесть при повышенных температурах. Построены кривые ползучести, которые позволили установить влияние напряжений и температуры на уровень деформаций при длительном нагружении.

В условиях длительного нагружения МКБВД одной из важных характеристик композитного материала оболочки является скорость установившейся ползучести. Результаты испытаний показали, что на данной стадии деформации монотонно увеличиваются по времени, а скорость ползучести близка к постоянной. Наибольшие значения скорости ползучести наблюдаются при температурах 90 и $110^{\circ} \mathrm{C}$. Рассчитана усредненная скорость стадии ползучести, которая может применяться в численных моделях для оценки ресурса МКБВД при длительной эксплуатации.

\section{Список литературы / References}

[1] Лепихин А.М., Москвичев В.В., Буров А.В., Анискович Е.В., Черняев А.П., Халиманович В.И. Экспериментальные исследования прочности и ресурса металлокомпозитных баков высокого давления. Заводская лаборатория. Диагностика материалов, 2019, 85(1), 49-56 [Lepikhin A.M., Moskvichev V.V., Burov A.V., Aniskovich E.V., Chernyaev A.P., Halimanovich V.I. Experimental study of strength and durability of metal-composite high-pressure tanks. Factory laboratory. Diagnostics of materials, 2019, 85 (1), 49-56 (in Russian)]

[2] Vasiliev V. V. Composite Pressure Vessels: Analysis, Design, and Manufacturing. Blacksburg, VA: Bull Ridge Publishing, 2009, 704 p.

[3] Kouadri BA, Imad A, Bouabdallah A, Elmeguenni M. Analysis of The Effect of Temperature on The Creep Parameters of Composite Material. Materials and Design, 2009, 30(5), 1569-74

[4] Dasappa P, Lee-Sullivan P, Xiao X. Temperature effects on creep behavior of continuous fiber GMT composites. Composite Part A: Applied Science and Manufacturing, 2009, 40(8), 1071-81

[5] Goertzen WK and Kessler MR. Creep Behavior of Carbon Fiber/Epoxy Matrix Composites. Materials Science and Engineering A, 2006, 421(1-2), 217-25

[6] Basaid D., Aribi C., Kari J., Benmounah A. and Safi B. A Comparative Study of The Creep Behavior of Laminated Composites: Effect of Type of Fiber and Matrix. Scientific Research and Essays, 2017, 12(6), 59-68

[7] Ascione F., Berardi V.P., Feo L. and Giordano A. An Experimental Study on The Long-Term Behavior of CFRP Pultruded Laminates Suitable to Concrete Structures Rehabilitation. Composites Part B: Engineering, 2008, 39(7), 1147-50

[8] Dong Yang, Jiwen Zhang, Shoutan Song, Fei Zhou and Chao Wang. Experimental Investigation on the Creep Property of Carbon Fiber Reinforced Polymer Tendons under High Stress Levels. Materials (Basel), 2018, 11(11), 2273 
[9] Янсон Ю. О., Дмитриенко И.П., Зелин В.И. Прогнозирование деформаций ползучести однонаправленно армированного органопластика по результатам квазистатических испытаний. Механика композитных материалов, 1983, 4, 610-613 [Yanson Yu. O., Dmitrienko I.P., Zelin V.I. Prediction of Creep Strains in Unidirectionally Reinforced Organoplastic Based on QuasiStatic Test Results. Mechanics of Composite Materials, 1983, 4, 610-613 (in Russian)]

[10] Sabah Khammass Hussein and Hussen Kareem Abdu Zahra. The Effect of Stress and Temperature Variation on the Creep Behavior of Epoxy Adhesive Bonding. Journal of Multidisciplinary Engineering Science and Technology (JMEST), 2016, 7, 5148-53

[11] Fei Zhou, Jiwen Zhang et al. Effect of Temperature on Material Properties of Carbon Fiber Reinforced Polymer (CFRP) Tendons: Experiments and Model Assessment. Materials (Basel), 2019, 12(7), 1025

[12] Фомин Н. Е., Ивлев В.И. Ползучесть твердой эпоксидной смолы. Физика и механика материалов, 2015, 22, 78-75 [Fomin, N.E, Ivlev V.I. Creep of solid epoxy resin Materials Physics and Mechanics, 2015, 22, 78-75 (in Russian)]

[13] Chengzhi Dong, Kai Li, Yuxi Jiang, Dwayne Arola and Dongsheng Zhang. Evaluation of thermal expansion coefficient of carbon fiber reinforced composites using electronic speckle interferometry. Optics Express, 2018, 26(1), 531-43

[14] Barrere C and Dal Maso F. Résines Époxy Réticulées Par Des Polyamines: Structure Et Proprieties. Oil \& Gas Science and Technology, 1997, 52(3), 317-35

[15] Москвичев Е.В., Еремин Н. В. Оценка механических свойств и толщины композитной оболочки металлокомпозитного бака высокого давления. Деформация и разрушение материалов, 2017, 12, 40-45 [Moskvichev E. V., Eremin N. V. Evaluation of Mechanical Properties and Thickness of Composite Shell of Metal-Composite High-Pressure Vessel. Deformation and Fracture of Materials, 2017, 12, 40-45 (in Russian)]

[16] Moskvichev E. V. Numerical modeling of stress-strain behavior of composite overwrapped pressure vessel. Procedia Structural Integrity, 2016, 2, 2512-2518

[17] Eremin N.V. Multiscale modeling of damage and fracture of a composite overwrapped pressure vessel. Journal of Physics: Conference Series. V International Scientific Conference «Survivability and Structural Material Science» (SSMS2020), 2021, 1023, 012010

[18] Васильев В.В., Мороз Н.Г. Композитные баллоны давления. Проектирование, расчет, изготовление и испытания. М: Машиностоение; Инновационное машиностроение, 2015, 373 с. [Vasilev V. V., Moroz N. G. Composite Pressure Vessels. Design, Analysis, Manufacturing and Testing. Moscow, Mashinostoenie, Innovacionnoe mashinostroenie, 2016, 373 p. (in Russian)]

[19] Jonathon D. Tanks, Katherine Rader and Stephen R. Sharp. Accelerated Creep Testing of CFRP with the Stepped Isostress Method. Mechanics of Composite and Multi-functional Materials, 2016, 7(46), 397-403

[20] Findley W.N., Lai J.S. and Onaran K. Creep and relaxation of nonlinear viscoelastic materials. North-HollandPublishing Company, 1976, 380 p.

[21] Humberto Almeida Jr., Heitor Luiz Ornaghi, Natalia Lorandi, Bernardo P. Bregolin, Sandro C. Amico. Creep and Interfacial Behavior of Carbon Fiber Reinforced Epoxy Filament Wound Laminates. Polymer Composites, 2017, 39(4), 2199-2206 